\title{
A RENOVAÇÃo URBANA do CENTRO de SÃo PAULO E O LARGO de SÃo BENTO
}

\author{
Helcio Ribeiro Campos *
}

Resumo: O objetivo deste artigo é mostrar parte de um programa de renovação urbana do Centro de São Paulo, conduzido por empresas privadas em associação com o poder público, exemplificado a partir do Largo de São Bento. Para a consecução disso, foi empreendido um breve estudo sobre a formação da centralidade e de sua posterior decadência, pois só nesta fase legitima-se um discurso intervencionista. Nesse contexto, são analisados alguns dos interesses sociais, econômicos, culturais e histórico-arquitetônicos, às vezes conflitantes, coexistentes na região central de São Paulo - envolvendo, por exemplo, camelôs, a Associação Viva o Centro, o vandalismo e a busca da produção de espaços higienizados e úteis ao turismo - à luz dos processos de revitalização, renovação e gentrificação. Tais processos se tornam imperativos sobre o Largo de São Bento por ser o local de origem de São Paulo e por representar um grande signo para a construção identitária e da memória da cidade, constituindo-se, portanto, em um foco especial para as intervenções urbanas e imprescindível para a abordagem geográfica.

Palavras-chave: renovação urbana; centralidade; Largo de São Bento; São Paulo; revitalização.

\section{THE RENEWAL OF SÃo PAULO CENTRE AND SÃO BENTO'S SQUARE}

\begin{abstract}
The aim of this article is to show a piece of one program on urban renewal of São Paulo Centre, led by private enterprises joined with public power, exemplifing since São Bento's Square. A short study about the formation of centricity and its farther deterioration has been made. Only in this stage justify an interventionist speech. Concerning them some social, economic, cultural and historical-architetonic interests are analysed. Sometimes they are in conflict, coexisting in São Paulo central area, surrounding peddler, Viva o Centro Association, the vandalism, and the search for hygienical space and good for tourism - through the process of revitalization, renewal and gentrification. These interests became so important about São Bento's Square because here is the beginning of São Paulo and by representing a great meaning on identity construction and city memory, them composed on a special focus to the urban interventions and essential on geographic approach.
\end{abstract}

Key Words: urban renewal; centricity; São Bento's Square; São Paulo.

\section{Introdução}

A cidade pode ser encarada como uma expressão da sociedade erigida na forma de um ambiente construído num espaço geográfico. Ela é uma materialidade evidente da estruturação dos processos sociais. Tais processos sociais são construtores de formas e fluxos no espaço, conferindo uma organização interna ao funcionamento das cidades. No topo dessa organização e dessa materialidade, estão as metrópoles, onde

* Mestre em Geografia Humana, USP. Professor do IFET - campus Barbacena, MG. Email: helcio.campos@ifsudestemg.edu.br 
coexistem diferentes formas de apreensão do uso da terra ao longo de sua história, diferenciados nas áreas centrais, residenciais, industriais e áreas de uso misto.

Entretanto, o foco deste trabalho recai na área central, especificamente da cidade de São Paulo, na qual o poder público, associado com empresas privadas cooptadas para um programa, tem por escopo a renovação do Centro histórico, onde se encontra o conjunto Faculdade-ColégioMosteiro de São Bento, que será observado em destaque.

Para a consecução disso, será apresentado um estudo preliminar sobre os processos de formação da centralidade e de sua posterior decadência, pois só nesta etapa legitima-se um discurso interventor.

Outro esclarecimento faz-se necessário: o termo renovação urbana será empegado para a área central como um todo. Renovação é a operação que exige demolição dos conjuntos originais, que é o caso do centro de São Paulo, alvo de várias intervenções ao longo do tempo. Por outro lado, processa-se também uma revitalização, ou seja, uma operação que muda a função de um edifício ou do espaço urbanístico, como é o caso das imediações do Mosteiro de São Bento, embora este mantenha sua mesma atividade histórica, aliás secular. Esses conceitos são derivados da apresentação feita por Eduardo Yázigi, em seu livro Civilização Urbana: planejamento e turismo (YÁZIGI, 2003, p. 89).

\section{A FORMAÇÃO DA CENTRALIDADE}

A área central de uma cidade é formada, e tantas vezes reformada, ao longo de sua história. Tal dinâmica, no entanto, tem o seu catalisador com o capitalismo e sua fase industrial, quando o Centro se alimenta da criação de ferrovias, o principal contato das cidades com o mundo exterior, ensina Lobato CORRÊA (1989, p. 38). Os terminais ferroviários localizavam-se o mais perto possível um dos outros e do porto, obviamente quando este puder existir. Porém, São Paulo não nasce industrial e nem dotada dessas externalidades. Ao contrário, as casas erguidas eram desalinhadas e o espaço público um palco da barbárie, com galinhas, porcos, etc. Eduardo YÁZIGI (2003, p. 170-171) indica que foi só a partir de 1780 que se tentou dotar a cidade de infraestrutura, inclusive no tocante à manutenção de caminhos e pontes. Nesse período, a cidade possuía poucas ruas e poucas construções davam um certo ar de urbanidade para São Paulo, dentre elas a do Mosteiro de São Bento, construído em 1598.

Somente no século XIX é que São Paulo, já sob a tutela dos ganhos com o café, irá mudar, modernizar-se. A arquitetura das taipas não se sustentava mais. O centro sofre profundas mudanças, com muitas demolições e renovações contínuas. Uma delas se dá com a criação do largo de São Bento, "o primeiro a ser projetado para este fim específico", tendo o Grande Hotel (1878) nas suas imediações, conforme YÁZIGI (2003, p. 176). Um dos ícones desta modernização seria a construção de estações ferroviárias, atestando o discurso sempre competente de L. Corrêa. Porém, a periferia foi abandonada. Criava-se uma cidade maquiada, com o Centro sendo um espelho do afã de se ter uma identidade "civilizada", leia-se europeia, portanto. É por isso que apenas em 1896 é criado o primeiro órgão disciplinador da vida urbana, a Comissão Técnica de Melhoramentos da Cidade. Embora São Paulo já contasse com a energia elétrica, as melhorias atendiam aos cafeicultores ricos. Ademais, não havia uma unidade nas construções (YÁZIGI, 2003, p. 183). 
Há um crescimento de bairros localizados nas imediações da ferrovia, pois tal área torna-se o principal foco do transporte intraurbano e inter-regional, emergindo uma área de acessibilidade dentro da cidade. Isso atraiu as nascentes lojas de departamento e o comércio varejista. Na área central, as empresas passam a dispor de externalidades (efeitos econômicos sobre as empresas e atividades que decorrem da ação de elementos externos a elas), seja decorrente da acessibilidade ou de estarem juntas, formando uma economia de aglomeração. Em razão de suas vantagens locacionais, o preço da terra e dos imóveis passa a ser maior no Centro (CORRÊA, 1989, p. 42).

São Paulo conheceria no século $X X$ um boom econômico. Porém, o fausto da economia não foi sentido na arquitetura, no sistema viário, na ambiência dos espaços públicos, entre outros fatores. Uma série de renovações pontuais marca uma contínua reconstrução de edifícios no centro da cidade, caracterizando uma verticalização acentuada com o tempo e que já contava com as primeiras construções em concreto no início do século $X X$. Obras de grande envergadura viária foram empreendidas, como aquelas do prefeito Prestes Maia e seu plano de avenidas, bem como as várias estações do metrô e suas "praças" remodeladas e/ou criadas (YÁZIGI, 2003, p. 185). Estas empreitadas consomem milhões e milhões dos cofres públicos, mas enfeiaram a cidade em certos casos ou deixaram marcas indeléveis na paisagem urbana, retirando a visão de espaços públicos, destruindo conjuntos arquitetônicos que traduziam uma fase histórica da cidade, aumentando a poluição sonora nas ruas e avenidas próximas, dificultando a locomoção pedestre, dentre tantos problemas causados. A cidade foi sendo projetada cada vez mais para a circulação dos automóveis, como nas ações malufistas, em detrimento dos interesses da maioria da população.

Desse modo, a identidade de São Paulo foi sendo desconstruída ao longo do século XX. Embora algumas preciosidades tenham sido elaboradas, como o Teatro Municipal (1912) e o Parque do Ibirapuera (1954, com projeto de Niemeyer), para citar exemplos apenas, o que restou foi uma cidade em frangalhos (YÁZIGI, 2003, p. 189).

A despeito de tanta insensatez, o Centro de São Paulo é o guardião daquilo que restou de todo esse aniquilamento. Constituiu-se como espaço privilegiado em acesso com transporte coletivo (metrô e ônibus), agrupou o comércio varejista e possui atualmente construções históricas que simbolizam a própria história da cidade. É importante perceber que se, hoje, pretendese uma renovação do Centro de São Paulo é porque tal área perdeu muito de seus status, sendo este o fator a ser investigado.

\section{A DECADÊNCIA NA ÁREA CENTRAL}

O núcleo central, também chamado de Central Business District- CBD, possui alguns aspectos que lhe são próprios e que funcionam como autodestruidores de seu prestígio, tais como: uso intensivo do solo, com maior número de atividades terciárias, legais ou não; ampla escala vertical e limitado crescimento horizontal; concentração de pessoas durante o dia e deserto à noite (área não residencial), colocando-o como espaço "propício" aos delitos; concentração de transportes do espaço intraurbano.

A área central tem sofrido um efeito de descentralização, pois atividades foram transferidas ou criadas fora daí a partir dos anos 1920, aproximadamente, e tendo se 
intensificado nos anos 50 e 60, período de fortes migrações internas no Brasil. Isso é prontamente verificado no Centro, "tomado" por nordestinos. A área central tende a uma redefinição funcional, tornando-se local de escritórios, enquanto o comércio varejista se espalha pela cidade (FRÚGOLI JR., 2000, p. 59).

Historicamente, 0 processo de descentralização é mais recente que o de centralização, sendo causado por estes fatores principais: aumento constante do preço da terra, dos impostos e dos aluguéis no Centro; congestionamentos frequentes; falta de espaço para expansão; restrições legais, pois não há um controle dos espaços do Centro, para onde afluem os camelôs, limitando a ação das firmas; ausência ou perda das amenidades, ou seja, a violência crescente contida nos núcleos centrais. Além desses, um fator fundamental é o da formação dos chamados subcentros.

A descentralização e a formação dos subcentros estão também associadas ao crescimento demográfico e espacial da cidade, ampliando as distâncias entre o Centro e novas áreas residenciais. É por isso que o transporte intraurbano é sempre tão importante nas decisões e projetos políticos, tal como no de Prestes Maia. A descentralização torna o espaço urbano mais complexo, com vários núcleos secundários. Para o consumidor, isso gera uma economia de transporte e de tempo, induzindo a um maior consumo e a uma dispersão do terceiro setor pela cidade. Portanto, os grandes projetos viários paulistanos podem ser percebidos à luz dos interesses do mercado.

Destarte, fica fácil concluir que a cidade possui processos segregacionistas, tanto em relação ao uso dos espaços como também pela presença de grupos sociais distintos.

\section{A SEGREGAÇÃO SOCIAL E ESPACIAL}

As áreas sociais são marcadas pela tendência à uniformidade da população, sobretudo aquelas de ordem socioeconômica (renda, instrução etc.) e étnico-cultural. A segregação é um processo que acena para uma organização espacial em áreas de forte homogeneidade social interna e de forte disparidade entre elas. As áreas centrais costumam abrigar características híbridas, deixando-as com uma grande complexidade, pois nelas coexistem interesses de mais de um grupo social, como ocorre em São Paulo.

É inegável que a parcela abastada da sociedade pode escolher onde morar. Primeiramente, os ricos moravam em chácaras. Posteriormente, passaram dos arredores para dentro da cidade, onde a infraestrutura passa a ser ampliada continuamente, sobretudo no Centro, seu local de maior urbanidade e palco maior da representação da civilização europeia nos trópicos. Quando as amenidades nas áreas centrais passam a declinar, as elites buscam novos locais de moradia nas cidades. Em outras palavras, os ricos se afastaram dos pobres, no início do século, por medo das doenças e, nas últimas décadas, em razão de uma "enfermidade" ainda maior: a pobreza.

Roberto L. CORRÊA (1989, p. 66) apresenta três padrões lógicos da segregação residencial: os esquemas de Khol, Burgess e Hoyt . O esquema de Hoyt revela uma cidade pré-industrial, com pouca mobilidade intraurbana. Burges apresenta o padrão da cidade no início do século $X X$, em que a elite passa progressivamente a abandonar 0 centro, onde as moradias são desvalorizadas, abrindo espaço para a ocupação das camadas 
populares locais e dos imigrantes. Hoyt mostra uma etapa em que a elite tende a uma autossegregação, escolhendo os locais com as maiores amenidades (embora isso seja também construído artificialmente, através da vigilância privada). A partir de sua ação estabelecem-se os demais estratos sociais. Na cidade latino-americana, segundo Lobato Corrêa, coexistem os três padrões de segregação mostrados.

Colocado isto, fica patente que o Centro apresentou múltiplas funções ao longo da história: abrigou a elite e sua materialidade (construções, parques etc.) e agora mantém diferentes atores sociais sob os símbolos urbanos mais identitários da capital dos paulistas. Aqueles que estão desejosos de ver uma renovação no Centro de São Paulo não estão pensando na população dos cortiços, mas no patrimônio histórico da arquitetura, nos monumentos e, claro, na formação de um símbolo que possa projetar uma imagem positiva da cidade. Há um interessante artigo de Oswaldo GUIMARÃES (1998) em que aborda o "sincretismo arquitetônico" de São Paulo, oferecendo uma sinopse e fotos de cerca de 15 edificações. E são estas e outras que "precisam" ser mudadas.

\section{A RENOVAÇÃo do CENTRO de sÃo PAULO}

Muitas metrópoles, em várias partes do mundo, estão passando por um processo de desconcentração industrial e populacional. A fim de suprir uma possível decadência econômica, David HARVEY (1992, p. 69) mostra que certas metrópoles promovem uma revitalização de suas áreas centrais, com o intuito de atraírem capital e pessoas (de classe média, por exemplo, mas desde que não fiquem os pobres, os encortiçados etc.), para o comércio e para o turismo, por meio de uma nova significação dos espaços urbanos.

Tais intervenções procuram atender a uma lógica do mercado, privilegiando os grupos sociais mais ricos, criando novas cisões no espaço urbano já tão fragmentado. Alguns autores, como FRÚGOLI JR. (2000, p. 22) e HARVEY (1992, p. 69-96), argumentam que decorre da renovação das áreas centrais um processo conhecido como gentrification enobrecimento - pois estas passam a ser ocupadas por pessoas de camadas sociais superiores a dos atuais moradores, que são, via de regra, "expulsos" para novas áreas. Mike Davis, citado por FRÚGOLI JR. (2000, p. 24), mostra uma série de estratégias para a eliminação dos pobres ou higienização, como expõem outros autores, tais como a implantação de praças, fontes, cafés, bares, concertos eventuais etc., propícios a turistas e aos trabalhadores brancos no Centro de Los Angeles, ao mesmo tempo em que se pretende afastar os pobres com a diminuição do número de banheiros públicos, a colocação de bancos que não se consegue deitar, vigilância e averiguação de abrigos etc.

Um dos motivos para a proposta de renovação do Centro de São Paulo é o de que essa área ajudou a forjar a história cultural da capital. Em meados do século XX, houve uma série de inaugurações e parcerias entre as instituições, dentre as quais estão o MASP, - MAM, a Escola Livre de Música, a Biblioteca Municipal e inclusive cursos ministrados por professores da USP, realizados no MASP, enfatiza Heitor FRÚGOLI JR. (2000, p. 5556).

Outra razão que fecunda a ideia de renovar o Centro é o abandono de vários monumentos e esculturas, mesmo que cerca da metade deles estejam somente neste espaço da cidade de São Paulo. É assim que entendemos $o$ porquê do processo de 
ressignificação dos símbolos presentes na área central. Como já exposto antes, os monumentos multiplicaram-se como uma afirmação da elite brasileira, expondo uma modernização urbana que se aproximasse do padrão europeu. O resultado desse esforço pode ser averiguado no artigo de Lauro MESQUITA (1998b, p. 36), que é assim apresentado: "Ao contrário de outras metrópoles, São Paulo trata muito mal seus monumentos em locais públicos". Apesar do vandalismo não ser novidade, houve uma certa insistência do poder público em construí-los, tais como no período da Revolução de 32, nas comemorações do quarto centenário de São Paulo e nos anos 1970, com a inauguração das primeiras estações de metrô.

É interessante perceber como há uma contradição nessas ações, pois a primeira gestão de Prestes Maia (1938-45) e a própria Companhia do Metrô são pródigas em maus exemplos, porque atuaram na desfiguração de espaços públicos na capital, ao mesmo tempo em que instalaram vários monumentos. Neste contexto, MESQUITA (1998b, p. 40) indica como parte de tal desleixo ocorreu, já que muitas obras de arte "tiveram" que ser transferidas (o elginismo), pois São Paulo foi palco de muitas e grandes intervenções urbanas. Ele aponta ainda outra preocupante situação, pois a desinformação levou o poder público a tentar fazer a limpeza regular de monumentos, que saíram danificados pelo uso de produtos corrosivos.

As esculturas do Centro estão submetidas a todo tipo de agressão, inclusive o do gradeamento. Como pensar em espaço público diante de um quadro estarrecedor? MESQUITA (1998b, p. 42) apontou para a descaracterização do Largo da Memória, que era um local de passagem e de permanência das pessoas e foi transformado numa via de trânsito de massas com a construção da estação Anhangabaú do metrô. Talvez aí tenhamos uma pista para o entendimento de um vandalismo ainda maior sobre 0 patrimônio cultural. Eduardo YÁZIGI (2002, p. 134) preocupa-se em incutir a ideia de que "(...) a paisagem interessa antes a seus próprios habitantes e que só numa relação de estima deles com ela é que despertará o interesse de transeuntes, visitantes, turistas". Este mesmo autor arremata a questão levantada, sendo categórico em afirmar que São Paulo é a metrópole com o pior espaço público do mundo (YÁZIGI, 2003, p. 200), inclusive pela permissividade por parte do poder público, que assiste à ação dos pichadores.

Num sentido mais amplo, trouxemos nossa história para o campo do anedotário. A historiografia nas últimas décadas foi rica em desconstruir uma identificação do brasileiro com seus personagens, ainda que muitos episódios possam desmerecer um altar de virtudes, mas levaram a uma banalização e o pior, a um desconhecimento de nossa formação sócio-histórica. Tal ideia é tributária de Mário Jorge PIRES (2002, p. 102), que explica tanta agressão aos monumentos e demais espaços: "A cidade de São Paulo vive hoje, entre tantos sérios problemas, a angústia da indefinição de sua Identidade Cultural; e esta é responsável pelo amor que o cidadão deposita em sua cidade $(.$.$) ".$

Em virtude desta complexa teia que cria e recria o Centro historicamente, surgem as propostas para um projeto que visa a sua renovação. Nos anos 1950, houve uma movimentação neste sentido no governo do prefeito Wladimir de Toledo Piza. Ele convidou o padre Louis Joseph-Lebret para um estudo sobre São Paulo. O Centro fora diagnosticado como já em ponto de saturação físico-econômica, pois a cidade era monopolar, o que atraía multidões. Enquanto o estudo proporia uma descentralização, os 
proprietários de edifícios no centro "(...) pretendiam revitalizá-lo, defendiam sua verticalização e faziam demandas pela reequiparação e ampliação do serviço de água, esgoto, sistema viário e transporte coletivo", segundo Libâneo, citado por FRÚGOLI JR. (2000, p. 57-58). Tal plano nunca seria implantado.

Contudo, daí para frente, o Centro manteve-se como local de investimentos públicos, mesmo com o processo de formação de novas centralidades em São Paulo, dentre os quais se destacam as obras de implantação do metrô, no governo Olavo Setúbal (1975-1979). Sua gestão foi responsável pelo Plano de Revitalização do Centro, que empreendeu uma "higienização" na Praça da Sé, com a tentativa de afastar os camelôs; criou ruas exclusivas para pedestres, os "calçadões"; restaurou locais de grande significação histórica e simbólica, como o edifício Martinelli, o viaduto Santa Ifigênia e o Pátio do Colégio; além "(...) da realização de um inventário das edificações de valor histórico, arquitetônico e cultural para posterior tombamento", nas palavras de Heitor FRÚGOLI JR. (2000, p. 63).

Em meio a todo este panorama traçado de complexidade, surge, em 1991, a Associação Viva o Centro - Sociedade PróRevalorização do Centro. Um dos fatores que impulsionou a criação da Viva o Centro foi o da fuga de empresas dessa região no limiar dos anos 90, sendo que as negociações para a manutenção das bolsas (Bovespa e BM \& F) serviu como um marco inicial, intermediado pelo capital financeiro, representado pelo Banco de Boston, através da iniciativa de seu então diretor, Henrique Meirelles, que, em 2011 (nos 20 anos da Associação), retornou ao cargo. Essa situação descrita poderia dar uma ideia de fragilidade econômica do Centro, o que não é verdade, pois constituíase em 1995, segundo dados da FIPE -
Fundação Instituto de Pesquisas Econômicas - , como a principal região geradora de empregos na cidade, contando com $24,7 \%$ de seus moradores com renda entre 5 e 10 salários mínimos (FRÚGOLI JR., p. 59-60).

A Associação Viva o Centro nasce sob a conduta da sociedade civil, fortemente marcada pela base empresarial, com presença de proprietários imobiliários e, posteriormente, vai ampliar seus colaboradores, incluindo apoio sindical. Apresenta uma certa heterogeneidade interna, embora tenha em comum uma pauta de reivindicações pela renovação central sem priorizar as camadas populares, além do discurso urbanístico que se afina com a presença da professora Regina Meyer. Sua proposta está pautada na ideia de um "urbanismo reparador", que prevê uma intervenção que dialoga com a realidade preexistente. Pensa-se no Centro de São Paulo sob a influência teórica de Jordi Borja e seu trabalho na recente intervenção realizada em Barcelona e, ainda, com uma necessidade de se transformar e adequar a novas necessidades prementes numa "cidade mundial" (FRÚGOLI JR., 2000, p. 218-219).

A inclusão da temática da globalização no discurso da Viva o Centro, sob o signo das cidades mundiais ou cidades globais, não traduz com certeza as influências específicas que a construção particularizada que cada cidade empreendeu. Em outros termos: é afirmar uma ideia que sirva para todos os casos. Além do mais, isso pode ser um discurso ideológico que está subjacente à consecução pragmática de coisas como a valorização de imóveis, por exemplo.

Adiante, os pressupostos da Associação Viva o Centro foram sendo incorporados ao programa do ProCentro, que possui ligação com a Prefeitura, embora este 
passe, na prática, a se afastar das propostas encaminhadas pela Associação.

Um tema fundamental quando se trata de uma renovação urbana é dos grupos sociais por ela abarcados. Geralmente são as camadas mais populares as visadas nesse tipo de planejamento. Existem duas grandes ideias a respeito: a primeira é aquela que pretende diminuir o número de pessoas circulando temporariamente pela área central, já que há uma excessiva convergência dos transportes coletivos nessa região, para chegar a uma diminuição da mendicância e do trabalho informalizado. A outra ideia incide na população que ainda "restaria" no Centro. Pretende-se limitar e legalizar a presença dos ambulantes, inclusive com o apoio do aparato policial. Eduardo YÁZIGI (2003, p. 211) cobra uma política habitacional efetiva do poder público nas zonas deterioradas e de baixa densidade nas imediações do Centro, como Bela Vista e Barra Funda, sobretudo porque a requalificação das áreas centrais tem sido realizada com base em parcerias que congregam várias entidades, dentre elas o Bank Boston, peça-chave na composição da Viva o Centro.

Muitos autores, entre os quais estão Yázigi e Frúgoli Jr., reconhecem que o trabalho informalizado, que será atingido pela renovação central, reúne em si antagonismos: de um lado, representa uma saída face ao desemprego e, de outro, uma interseção com o crime, com o caixa dois de empresas, e com a política, através do apoio de vereadores, por exemplo. Apesar de tudo isto, Heitor Frúgoli Jr. posiciona-se claramente a favor dos camelôs e contrário à proibição do comércio informal (2000, p. 16), conforme atesta Lúcio Kowarick, o prefaciador de seu livro Centralidade em São Paulo: trajetórias, conflitos e negociações na metrópole. Consideremos isto: a realidade é complexa e suscita as dúvidas!

Ainda que seja temerário fazer conjeturas sobre o futuro da organização espacial do Centro de São Paulo, é justo pensar que, a par de tudo que já foi exposto, poderemos assistir a um processo também de reorganização social deste espaço, ou seja, seu enobrecimento (gentrification). Isso é possível pois a renovação e a revitalização pretendidas podem mudar o valor da terra, catapultando-o para valores mais altos, o que atrairia atividades culturais, comércio e outros serviços para classes de maior poder aquisitivo. Tal fato pode se constituir numa forma eufemista, sem uso de violência, de retirada dos pobres da região central. Efetivadas tais mudanças, haveria um espaço para a utilização da região como espaço turístico, sobretudo com a expectativa de maiores amenidades e melhores serviços.

Traçadas as linhas gerais que orientam as modificações no Centro, entra em cena uma abordagem mais pontual, a do Largo de São Bento, sobretudo o Mosteiro.

\section{A REVITALIZAÇÃO DO LARGO DE SÃO BENTO}

Este pequeno espaço no Centro de São Paulo congrega o conjunto FaculdadeColégio-Mosteiro de São Bento, tendo a estação de metrô nas suas adjacências, que tomou-lhe o nome emprestado. Apesar de pequena, trata-se de uma área de grande significação para a construção da história e da identidade cultural paulistana.

\section{BREVE HISTÓRIA DO MOSTEIRO DE SÃO BENTO}

Pode-se dizer que o sítio histórico que abriga o Mosteiro é o mais antigo de São 
Paulo. A instituição completou, em 1998, 400 anos de ocupação ininterrupta no mesmo local. Cabe lembrar que o Pátio do Colégio, marco de fundação da cidade, passou por várias transformações, sendo que, entre 1765 e 1932, abrigou o Palácio do Governo.

O Mosteiro foi fundado em 14 de julho de 1598, ficando exatamente no alto da elevação (preocupação com a defesa do local), entre os rios Anhangabaú e Tamanduateí, abrangendo de um lado o Vale do Anhangabaú e, do outro, até a atual rua 25 de Março. A fundação ficou a cargo de Simão Luís, ou frei Mauro Teixeira, que conheceu o cacique Tibiriçá, erguendo sobre a antiga taba deste índio uma igreja em homenagem a São Bento.

Graças a Fernão Dias Paes foi construído, a partir de 1650, um novo templo. Seus restos mortais e os de sua esposa encontram-se na cripta do Mosteiro. Desta época datam também as imagens de São Bento e Santa Escolástica, de autoria do frei Agostinho de Jesus, e que vemos até hoje na basílica.

Em julho de 1900, D. Miguel Kruse assume a direção do Mosteiro e inicia um novo período na história de São Paulo. Seus primeiros esforços são no sentido de dotar o mosteiro de um bom colégio secundário. Surge assim, em 1903, o Colégio de São Bento, que ainda permanece sob a administração da Ordem. O termo "ainda" foi incluído, pois não se sabe ao certo sobre seu futuro e demais informações foram negadas na realização deste estudo. Logo após, em 1908, funda-se a Faculdade de Filosofia, que seria a primeira do Brasil e que, atualmente, encontra-se ligada à PUC de São Paulo. Em 1911, instala a primeira abadia de monjas beneditinas da América do Sul, o Mosteiro de Santa Maria.

É também de iniciativa de D. Miguel Kruse, a construção de uma nova abadia e um novo mosteiro. Em 1910, tem início a nova construção segundo projeto do arquiteto Richard Berndl, da cidade de Munique, Alemanha. Em 1914, estava completado 0 conjunto beneditino que conhecemos hoje, abrigando a Basílica de Nossa Senhora da Assunção, o Mosteiro e o Colégio de São Bento, marco histórico, cultural e turístico da maior importância para a cidade de São Paulo e para o Brasil.

Esse é o texto básico disponível no site do Mosteiro, ao qual algumas informações foram incluídas.

\section{O INTERESSE PELA}

\section{REVITALIZAÇÃO E OS ATRATIVOS DO} LARDO DE SÃO BENTO

A quem interessaria a revitalização do Largo de São Bento? Num primeiro momento imaginamos que o conjunto esteja no imaginário geral da população e, sendo assim, todos se irmanariam em apoio ao projeto. Entretanto, vivemos sob a lógica do lucro, capaz de guiar os olhos para a beleza arquitetônica e também para o consumo.

Como reconhece o próprio texto oriundo do Mosteiro, há um interesse turístico e histórico pelo Largo. Tal potencial foi ainda mais incentivado devido aos programas introduzidos no início dos anos 1990. Com aportes de capitais (cujos valores não foram divulgados pelo Mosteiro) do Bank Boston, houve uma revitalização do Mosteiro, enquanto a Philips do Brasil ficou por conta do reaparelhamento da iluminação.

A visitação à basílica não é registrada e, assim, não há como quantificá-la, embora seja perceptível a presença de turistas. No seu interior, deslocado à esquerda, há uma pequena loja de artigos gastronômicos e de materiais de divulgação religiosa, incluindo cartões-postais do Mosteiro. 
A tradição gastronômica está ligada diretamente a São Bento que, no século VI, adverte seus monges para a construção de um mosteiro que possuísse padaria, horta, pomar... Para ele, valia o lema ora et labora, oração e trabalho. A abadia beneditina de São Paulo não fugiu à regra. Passou a oferecer ao público, a partir de 1999, o Bolo dos Monges (banana, ameixa e leite condensado; vendido a $\mathrm{R} \$ 50,00$ ), servido para estes no café da manhã. O sucesso levou ao lançamento, no ano posterior, do Bolo Santa Escolástica (maçã, nozes e canela, a R\$60,00), cuja receita suíça-alemã data do século XVIII, é tradicionalmente servido nos períodos da Páscoa e do Natal. Em 2001, o Pão de São Bento (pão salgado de mandioquinha) foi lançado e sua "tiragem" desaparece com rapidez das prateleiras da boulangerie. Um dos últimos lançamentos foi o do Pão de Mel Benedictus (com recheio de framboesa), já popular. Marcelo AZAMBUJA (2000, p. 73) afirma que dentre as razões que explicam a permanência do apego a alimentos tradicionais ou locais, estão as de ordem material e as de ordem simbólica. Esta última ordem confirma a tradição gastronômica do Mosteiro. Assim, a "transmissão de hábitos alimentares cotidianos ou de eventos, como Natal e Páscoa, é uma forma de coesão social e prova de autenticidade cultural".

Todas as receitas são seculares e guardadas sob sigilo, sendo só transmitidas a um outro monge para dar continuidade aos pressupostos de São Bento: "são verdadeiros monges, se vivem do trabalho de suas mãos", conforme disponível no site do Mosteiro. Existem informativos, disponibilizados para o público, sobre as iguarias, a história do Mosteiro e também sobre o funcionamento da basílica, incluindo os dias e os horários em que há canto gregoriano. Apesar de haver um autorreconhecimento por parte do Mosteiro, sobre o interesse dos turistas em visitar a basílica, esta fica fechada todas as quintasfeiras das 8 às $11 \mathrm{~h} 30$ min.; que geralmente não é o dia da semana com a menor demanda. Em 2009, a padaria do mosteiro, ao completar 10 anos de atividades, abriu sua primeira filial no bairro do Jardim Paulista. Em 2007, as suas iguarias serviram ao Papa Bento XVI, em sua passagem pelo Mosteiro de São Bento.

Outra riqueza inestimável, embora não esteja disponível para os olhos do transeunte, é o acervo de cerca de $80 \mathrm{mil}$ volumes da biblioteca do Mosteiro, acumulados nos seus 400 anos de história. Existem livros raros. O mais antigo data de 1500, uma edição dos Sermones des Sanctis, de Pelbart de Temesmar. A primeira das duas salas é basicamente composta por livros sobre hagiografia, a vida dos santos; e a segunda, com periódicos, dentre os quais um dirigido por Eça de Queiroz, com mais de 800 páginas, que circulou entre 1889 e 1892. Lá também estão as coleções de missais - os livros de partituras com canto gregoriano - e de antifonais, partituras para vesperais e outros rituais do Mosteiro. Apesar de não ter as soleiras diante da rua, as portas da biblioteca se abrem, inclusive para pesquisadores (MESQUITA, 1998a, p. 49-52).

Um fator fundamental para a frequentação do Largo é o da acessibilidade. A estação São Bento do metrô possui uma saída defronte ao Mosteiro. Outro fator é o das amenidades: percebe-se que há um posto policial disposto a poucos metros do Mosteiro. Aliás, esta é uma preocupação evidenciada para toda a área central tornarse realmente uma região renovada e composta de novos significados para a população.

Nestes termos, o espaço interno da estação São Bento do metrô sofreu uma 
revitalização nos últimos dez anos. Há uma ocupação com lojas do terceiro setor, inclusive estabelecimentos bancários, além de bares e serviços, como de acesso à internet. A interpretação que se pode fazer é que este padrão de uso econômico na estação comprova toda uma intenção de se remodelar a vida social e a frequentação nas regiões centrais de São Paulo.

No que se refere à atração das pessoas, o Mosteiro realizou algumas edições do Festival Internacional de Órgão. Não que ele seja organizado para isto, mas possui um poder de atração. Este evento conta, na sua história, com participações internacionais e tornou-se um marco na vida cultural paulistana. Por outro lado, a cultura também funciona como um meio de segregar a população. Não por acaso, existem programações musicais, de danças etc., também no espaço interno da estação São Bento do metrô.

Ao que tudo indica, muitas ações pontuais, como esta apresentada acerca do Largo de São bento, não representam um mosaico ou uma fragmentação, mas indicam um conjunto de locais que, em atividades separadas, poderão arregimentar um território cujo poder será o da rentabilidade econômica e com uma nova população.

\section{QUERENDO, QUERO O INFINITO. FAZENDO, NADA É VERDADE.}

Concluo tomado pelo assombro da inércia de nossa sociedade. Individualmente não me sinto contente com tal comportamento, assim como a autocrítica de Fernando Pessoa. Socialmente, componho um grupo com capacidade para compreender o mundo ao seu redor, num país com milhões de iletrados. Talvez pudéssemos seguir o exemplo de W. Bunge, que fez de seus ensinamentos uma geografia presente nos locais em que - não que ela fosse imprescindível - representasse parte de uma esperança. Quanto ao nosso estado ético, penso que a aventura científica digna dos estudos acadêmicos poderá afastar a angústia que tomou o poeta na sequência de seus versos: Que nojo de mim me fica / Ao olhar para o que faço / Minha alma é lúcida e rica, / E eu sou um mar de sargaço.

Acredito que o Centro continuará, ainda que a ideia subjacente ao plano de sua renovação seja a de obter um enobrecimento (gentrification), abarcando diferentes grupos sociais e, portanto, interesses diferenciados que poderão criar um novo arranjo de forças para o futuro. Mesmo com a renovação e com a revitalização de vários edifícios, o Centro permanecerá um mosaico de estilos arquitetônicos e de pessoas vivendo ou transitando num espaço público ainda de baixa qualidade. E não se pode esquecer que o Largo de São Bento é uma das portas para a observação desse devir urbano.

Temos que imaginar qual será o destino funcional do Centro e para onde irá sua população pobre. Talvez isso seja uma parte nobre da ciência, que the confere responsabilidades. Neste contexto, São Paulo precisa de políticas - como a habitacional, por exemplo - que aproximem o cotidiano de pessoas de diferentes espaços intrametropolitanos, obviamente com maior qualidade.

Seria muito pretensioso de minha parte afirmar qual será o resultado das mudanças pelas quais o Centro vem passando, embora tenha feito algumas considerações e conjeturas. Estou com o Pessoa: Vontades ou pensamentos? / Não o sei e sei-o bem. 


\section{REFERÊNCIAS BIBLIOGRÁFICAS}

AZAMBUJA, Marcelo. "A gastronomia como produto turístico" (p. 69-75). In: CASTROGIOVANNI, A. Carlos (org.). Turismo urbano. $1^{\text {a }}$ edição. São Paulo: Contexto, 2000, 111 p.

CORRÊA, R. Lobato. O espaço urbano. $3^{a}$ edição. São Paulo: Ática, 1989, 94 p.

CORRÊA, R. Lobato. Trajetórias geográficas. $3^{a}$ edição. Rio de Janeiro: Bertrand Brasil, 1997, 304 p.

FRÚGOLI JR., Heitor. Centralidade em São Paulo: trajetórias, conflitos e negociações na metrópole. $1^{\text {a }}$ edição. São Paulo: Cortez/EDUSP, 2000, 264 p.

GUIMARÃES, Oswaldo. História construída. Urbs, ano I, n 9, set/out de 1998, p. 38-47.

HARVEY, David. Condição pós-moderna. $5^{a}$ edição. São Paulo: Loyola, 1992, 352 p.

HUET, Bernard et al. Os centros das metrópoles: reflexões e propostas para a cidade democrática do século XXI. $1^{\text {a }}$ edição. São Paulo: Terceiro Nome/ Viva o Centro/Imprensa Oficial do Estado, 2001, $199 \mathrm{p}$.
MESQUITA, Lauro. A biblioteca do Mosteiro. Urbs, ano I, no 9, set/out de 1998a, p. 4853.

MESQUITA, Lauro. Tristes monumentos paulistanos. Urbs, ano II, no 10, nov/dez 1998b, p. 36-43.

PIRES, M. Jorge. Lazer e turismo cultural. $2^{a}$ edição. Barueri: Manole, 2002, 130 p.

SPOSITO, M. E. Beltrão. O centro e as formas de expressão da centralidade urbana. Revista de Geografia, v. 10, 1991, p 1-18.

YÁZIGI, Eduardo. "Vandalismo, paisagem e turismo no Brasil" (p.133-155). In: YÁZIGI, E., CARLOS, Ana F. A. \& CRUZ, R. de Cássia. Turismo: espaço, paisagem e cultura. $2^{\mathrm{a}}$ edição. São Paulo: Hucitec, 2002, 242 p.

YÁZIGI, Eduardo. Civilização urbana, planejamento e turismo: discípulos do amanhecer. $1^{\text {a }}$ edição, São Paulo: Contexto, 2003, 359 p. 